\title{
Robótica Pedagógica: Uma Reflexão sobre a Apropriação de Professores da Escola Elza Maria Pellegrini de Aguiar
}

\author{
João Vilhete Viegas d'Abreu ${ }^{1}$, Bruno Leal Bastos ${ }^{2}$ \\ ${ }^{1}$ Núcleo de Informática Aplicada à Educação - Universidade Estadual de Campinas \\ (NIED/UNICAMP), Caixa Postal 6082-13.083 - 970 - Campinas - SP - Brazil \\ ${ }^{2}$ Universidade Estadual de Campinas (IA/UNICAMP) - Campinas - SP - Brazil \\ jvilhetedunicamp.br, bruno. leal.bastosegmail.com
}

\begin{abstract}
Since the beginnings of computer use in education pedagogical robotics has contributed as a resource that helps, empowers and diversifies this use. Therefore, the practice of robotics has enabled the diversification way to introduce information technology in education. In the project context One Laptop per Child (UCA), Ministry of Education - MEC that is no different. The UCA has been an interesting space research in the use of educational laptop classmate aiming the consequent integration of this resource to the teaching-learning process in Brazil. One of the initiatives of the UCA-UNICAMP in Escola Elza Maria Pellegrini de Aguiar (Escola Elza) has been the practice of pedagogical robotics included into the curriculum in elementary school. For this practice, it was necessary also in the training of teachers in computer usage classmate introduce robotics educational activities. The process of training teachers for the appropriation of knowledge of robotics as a teaching resource became an exciting challenge which was attended and still attend students, university researchers, and the direction of the school Elza. This article aims to present, briefly, few joints that involve the process of training teachers for the appropriation of knowledge of robotics as a teaching resource articulate the curriculum of elementary school.
\end{abstract}

Resumo. Desde os primórdios de uso do computador na educação a robótica pedagógica tem contribuído como recurso que auxilia, potencializa e diversifica esse uso. Portanto, a prática da robótica tem possibilitado a diversificação, a forma de se introduzir a informática na educação. No contexto do projeto Um Computador por Aluno (UCA), do Ministério da Educação - MEC isso não é diferente. O UCA tem sido um espaço interessante de pesquisa no uso de laptop educacional classmate visando a consequente integração deste recurso ao processo de ensino-aprendizagem no Brasil. Uma das iniciativas do UCA-UNICAMP na Escola Elza Maria Pellegrini de Aguiar (Escola Elza) tem sido a prática da robótica pedagógica inserida ao currículo no Ensino Fundamental I. Para tal prática, fez-se necessário também, na formação de professores no uso do computador classmate introduzir atividades de robótica pedagógica. O processo de formação dos professores para a apropriação dos conhecimentos da robótica como recurso pedagógico se constituiu em um desafio interessante do qual participaram e ainda participam pesquisadores da universidade, alunos, professores e a direção da escola Elza. Este artigo tem como objetivo apresentar, de forma sucinta, algumas articulações que envolvem o processo de formação de professores para a apropriação do conhecimento da robótica como recurso pedagógico articulado ao currículo do Ensino Fundamental I. 


\section{Introdução}

No contexto do projeto Um Computador por Aluno (UCA), a formação de professores e alunos tem buscado, a partir da realidade da escola produzir, com base no currículo, conhecimentos científicos que auxiliem, de forma prática e concreta, o aprendizado de conceitos, que na maioria das vezes são somente anunciados e nunca trabalhados de forma contextualizada. Mais informações sobre o UCA podem ser obtidas no site [www.uca.gov.br/institucional/projeto.jsp]. Uma das atividades em andamento, neste processo, é a formação dos professores para a apropriação dos conhecimentos de robótica integrados ao currículo. Esta atividade, que tem sido realizada em sala de aula envolvendo a participação dos alunos, difere do processo tradicional de formação realizado fora do contexto da sala de aula. Ou seja, formação desvinculada do conteúdo curricular, para posteriormente ser inserida no currículo.

Atividades de robótica pedagógica na Escola Elza Maria Pellegrini de Aguiar têm buscado trabalhar a formação para que professores e alunos se apropriem de conhecimentos do uso de laptop classmate, associados à construção de dispositivos robóticos controlados por esse computador. Isso tem propiciado aspectos interessantes, nesse contexto de ensino aprendizagem que associa, o uso do laptop educacional como tecnologia móvel e construção/invenção de máquinas que estão no imaginário das crianças. Esse processo tem buscado contribuir com este lugar privilegiado do saber, que é a escola, onde os profissionais necessitam de um aprendizado complementar, contínuo e de qualidade [Passos 1997]. Neste sentido, o desafio é a melhoria do Ensino Público com base em um projeto voltado para a formação na ação dos professores, possibilitando que estes efetivamente melhorem suas práticas, na medida em que o desenvolvimento profissional orienta o desenvolvimento curricular [Garcia 2002]. Este desafio tem se dado em contextos nos quais alunos e professores aprendem, de forma concomitante e interdisciplinar, conteúdos curricular, construção de dispositivos robóticos e uso de laptop classmate para controlar os dispositivos construídos [d'Abreu, Bastos e Giachetto 2012]. Do ponto de vista de pesquisa no UCA-UNICAMP, a robótica pedagógica tem sido uma atividade que envolve a construção de dispositivos robóticos cujo processo de implementação implica na aplicação, de forma interdisciplinar, de conhecimentos de Física, Matemática, Geografia, Química, Português, História, dentre outras áreas de conhecimento. Esses conhecimentos são apresentados de maneira simples, passíveis de serem compreendidos por alunos do Ensino Fundamental I. Isso tem possibilitado a interação entre professores da escola pública e pesquisadores, da universidade da área de informática na educação, no desenvolvimento de ambientes que conciliam o concreto e o abstrato; aspectos lúdicos; jogos digitais, dentre outras abordagens, para criar situações de aprendizagem, e resolver problemas, que envolvem: concepção, implementação, construção, automação e controle de um mecanismo [Zanetti, et al 2012]. Na concepção do dispositivo é discutido o seu design, o porquê de se construir aquela máquina para realizar uma determinada tarefa. Na implementação, a discussão se dá em torno de como este robô deve ser construído: com material de kits de montar, material alternativo do tipo sucata ou uma mistura dos dois e, que componentes mecânicos eletroeletrônicos o robô deve possuir para funcionar [d'Abreu, Ramos e Mirisola 2011]. Na construção, o trabalho consiste na montagem do robô propriamente dito, utilizando e respeitando princípios mecânicos e elétricos que fazem uma máquina funcionar. $\mathrm{Na}$ automação e controle, a 
tarefa consiste em utilizar um software com um ambiente de programação adequado e comandos apropriados para controlar componentes eletroeletrônicos do robô, desenvolvendo programa que faça com que o robô realize de forma automática a tarefa para a qual ele foi projetado. Isso tudo é feito com vistas a explorar tanto a vertente de construção quanto a de programação [Miranda, Sampaio e Borges 2010]. Em todas as etapas desse processo pode e deve ocorrer aprendizagem. Aprendizagem essa advinda das mais diferentes áreas científicas fazendo emergir novas ideias tecnológicas capazes de serem apropriadas pelos professores e alunos e produzir novos conhecimentos [Papert 1994]. É nesse contexto de formação, que se enquadra o processo de implantação e uso da robótica pedagógica na escola como atividade de pesquisa envolvendo alunos professores, e também a direção da escola Elza. O artigo destaca duas fases distintas de formação a primeira, desenvolvida entre agosto de 2011 e dezembro de 2012, pode ser denominada de formação intensiva, na qual houve uma atuação mais sistemática com a presença constante, de pesquisadores da universidade junto aos professores e alunos da escola Elza. Uma espécie de atuação "corpo-a-corpo". A segunda fase que ainda está em execução, iniciou-se em julho de 2013, ela consiste de uma atuação não mais com presença constante dos pesquisadores da universidade na escola, e sim de um acompanhamento à distância e, visitas esporádicas a escola em momentos específicos. Portanto, este artigo tem como objetivo apresentar, algumas articulações que envolvem o processo de formação de professores para a apropriação do conhecimento da robótica como recurso pedagógico articulado ao currículo. $\mathrm{O}$ artigo está assim organizado: Na seção 1 apresentou-se uma contextualização do projeto UCAUNICAMP no processo de formação dos professores; na seção 2, está apresentada a metodologia de trabalho desenvolvido; na seção 3, descrição de uma das aulas; na seção 4, resultados e discussão e, por fim, na seção 5, as conclusões do trabalho.

\section{Metodologia Do Trabalho Desenvolvido}

Faz parte do ambiente de robótica pedagógica o uso de componentes eletroeletrônicos (motores, sensores, luzes, dentre outros), peças mecânicas que permitem construir mecanismos que se movimentam e ferramentas de hardware e software para automação destes mecanismos [d'Abreu e Garcia 2010]. Além disso, também é necessário o desenvolvimento de uma proposta pedagógica capaz de propiciar situações de aprendizagem em que conceitos científicos podem ser trabalhados de forma interdisciplinar. Portanto, é requerido um contexto para o desenvolvimento metodológico de experimentos que possibilite agregar conteúdo curricular à atividade de se fazer robótica pedagógica. Neste sentido, do ponto de vista metodológico, numa perspectiva de pesquisa qualitativa, utilizando como instrumentos para coleta de dados filmagens, fotografias e registros escritos, o processo de formação dos professores pode ser dividido em duas fases distintas, primeira e segunda.

\subsection{Primeira Fase}

A primeira fase foi desenvolvida de agosto de 2011 a dezembro de 2012. Esta, por sua vez, pode ainda ser subdividida em duas etapas, que serão sucintamente descritas a seguir. 
2.1.1 Etapa 1: Realização de Oficinas Piloto pelos pesquisadores da universidade para todos os professores e a direção da escola Elza.

Esta etapa ocorreu de agosto a dezembro de 2011, durante esse período foram realizadas as interações iniciais com a escola que tinham como objetivo, por meio de Oficinas Piloto de Demonstração, apresentação de vídeos; palestras e discussões; a sensibilização da escola para o uso da robótica pedagógica com classmate, como forma diferenciada de se explorar o uso deste computador. Com esta ação o que se buscava na realidade era que surgissem, voluntariamente, professores interessados em trabalhar com a robótica. Nesta etapa, a direção escolar convidou além de 10 professores da escola, alunos monitores para participarem. Alunos monitores eram alunos de ensino fundamental I e II, de diferentes faixas etárias, que durante o período contrário ao de aulas aprenderam a operar o classmate e passaram a auxiliar os professores nas tarefas de apropriação e uso desses computadores na classe. Formado então o grupo, constituído de alguns professores e alunos monitores, passou-se ao desenvolvimento de oficinas com este grupo. Eram oficinas de 02 horas, realizadas no laboratório de informática da escola. As oficinas eram de montagem de dispositivos robóticos, elaboração de programas usando a linguagem de programação Scratch, ensino dos princípios básicos de controle de componentes eletroeletrônicos via computador e de princípios mecânicos das máquinas que estão no nosso dia a dia. Ao longo deste processo, tanto as professoras quanto os alunos monitores se mostravam extremante receptivos, envolvidos e interessados na implantação da robótica pedagógica na escola, entretanto, no final do processo, somente duas professoras do $5^{\circ}$ ano se interessaram efetivamente em trabalhar com a robótica e é com estas que as atividades vêm sendo desenvolvidas. As atividades desta etapa tiveram como desdobramento dois fatos interessantes de se ressaltar, o primeiro, foi à participação dos alunos, apresentando projetos desenvolvidos durante as oficinas, no Evento "Arena Digital" promovido pela Câmara Municipal de Campinas, em setembro de 2011. Este foi um momento importante para a escola que pôde se mostrar para o público apresentando algo diferente do tradicional. Segundo, com as repercussões do projeto de robótica na escola e na comunidade a direção escolar se empenhou em angariar recursos para aquisição de material próprio para desenvolver atividades de robótica. Até então, utilizavam material da universidade. Em dezembro de $2011 \mathrm{deu}$-se por concluído esta etapa.

\subsubsection{Etapa 2: Realização de Oficinas na sala de aula com as turmas de $5^{\circ}$ Ano A e B}

Esta etapa ocorreu de março a dezembro de 2012. Entre março e junho as atividades foram desenvolvidas com a professora e alunos do $5^{\circ}$ Ano A e de agosto a dezembro com os do $5^{\circ}$ Ano B. As oficinas desta etapa eram de 02 horas de duração, realizadas semanalmente na classe, pelos pesquisadores da universidade, com a participação de todos os alunos e da professora daquela classe. Os alunos eram divididos em grupos de modo a permitir que tivessem acesso a todas as atividades do ambiente de robótica pedagógica (design, construção, automação-programação e controle do dispositivo robótico). O item 3 deste artigo apresenta a descrição de uma das aulas desenvolvidas nesta etapa. Durante a realização desta etapa, para cada oficina ministrada, as professoras e os alunos tinham como tarefa de casa elaborar um relato, memórias do que foi trabalhado naquele dia. Uma análise dessas memórias será objeto de estudo a ser apresentado em outro artigo. Em síntese, a primeira fase do processo de formação das professoras e alunos, com o objetivo de se integrar robótica pedagógica ao currículo, foi 
de atuação mais sistemática, de pesquisadores da universidade junto às professoras e alunos, buscando criar condições que possibilitassem a realização em sequencia, da segunda fase. Entretanto, de dezembro de 2012 a maio de 2013, em função dos acertos específicos inerentes ao projeto UCA, como um todo, não foram desenvolvidas atividades de robótica na escola. A segunda fase está descrita a seguir.

\subsection{Segunda Fase}

A segunda fase iniciou-se em junho de 2013 e ainda está sendo implementada, no momento, consistindo na preparação das professoras para desenvolverem sozinhas atividades regulares de robótica pedagógica, integrada ao currículo, sem a sistemática presença física dos pesquisadores da universidade na escola. Entretanto, embora os pesquisadores não estejam presencialmente, de forma constante na escola, como ocorreu na primeira fase, foi estabelecido um canal de comunicação permanente entre estes e as professoras. As discussões e orientações sobre o desenvolvimento de atividades têm se dado fundamentalmente, via e-mail. Ficou acordado que nesta segunda fase seriam realizadas visitas esporádicas, dos pesquisadores, à escola em situações que envolvessem ações mais complexas, como por exemplo, troca de versão de sistema operacional para controle da interface eletrônica dos kits de robótica, ensino de uso de novos componentes eletroeletrônicos e realização de reuniões, demandadas pelas ações do projeto ou, solicitadas pela escola. Para esta fase foi elaborado um material básico de apoio que descreve, com detalhe, as entradas e saídas da interface eletrônica que controla os componentes eletroeletrônicos via laptop classmate. Este material de apoio contem exemplos, com desenhos, de conexão de motores, sensores e lâmpadas na interface eletrônica, exemplo de programas em Scratch, para acionamento e controle de componentes eletroeletrônicos, dentre outros, que possam ajudar a professora a resolver eventuais problemas de ordem técnico-pedagógico durante a aula. Além disso, ainda com vistas à preparação das professoras para esta fase, se realizou alguns encontros na escola que se constituíram na atualização e recapitulação de conteúdos que haviam sido trabalhados com elas até final de dezembro de 2012. Na operacionalização desta prática, que está acontecendo agora, no segundo semestre de 2013, as professoras resolveram inserir outro desafio no processo. Selecionaram alguns alunos para atuarem como monitores da própria turma ajudando-as nas atividades de robótica. Esses alunos estão sendo formados pelas professoras que apostam na ideia de que já adquiriram conhecimentos para tal. Esse desafio das professoras possui algo de muito positivo que é o fato de se sentirem seguras para trabalharem a robótica pedagógica e passarem esta segurança para seus alunos numa relação em que estes poderão vir a atuar de igual para igual com as professoras ensinando os seus próprios colegas de classe. Até final de 2013 teremos o resultado desta prática desafiadora. Do ponto de vista metodológico, nas duas fases descritas foram realizadas a preparação das professoras para assumirem sozinhas, de forma autônoma, o controle/comando das atividades de robótica com suas classes. Em resumo, a metodologia desenvolvida neste processo de formação consistiu na realização de Oficinas Piloto de Demonstração apresentação de vídeos palestras e discussões, sensibilização de professores alunos e direção escolar, atividades de formação de duas professoras e os respectivos, acompanhamentos presenciais de pesquisadores da universidade $\mathrm{e}$, finalmente, o trabalho das professoras com acompanhamento a distância dos pesquisadores da universidade. A seguir a descrição de uma das aulas. 


\section{Descrição de uma das aulas}

A título de exemplo de atividade em desenvolvimento na escola, no contexto do processo de formação dos professores e alunos, foi apresentado à classe de alunos de $5^{\circ}$ ano (crianças na faixa etária de 08 a 11 anos) o desafio de construir um carro que pudesse transportar o laptop classmate, conforme mostrado na figura 1 .

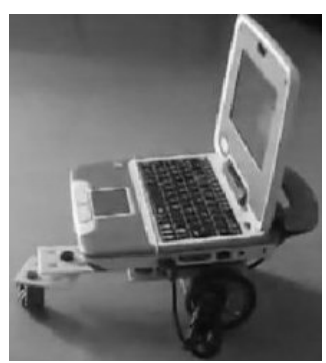

\section{Figura 1. Carro robô transportando classmate}

O desafio apresentado tinha a ver com o fato de que no currículo da escola os alunos do $5^{\circ}$ ano estavam estudando unidades de medida. O processo de construção do carro, como mostrado na figura 2, consistiu em montar uma estrutura composta de uma base (chassis), no qual se pudesse fixar dois motores para giro e tração traseira das rodas. Uma roda dianteira, sem tração, servia de apoio e de direção.

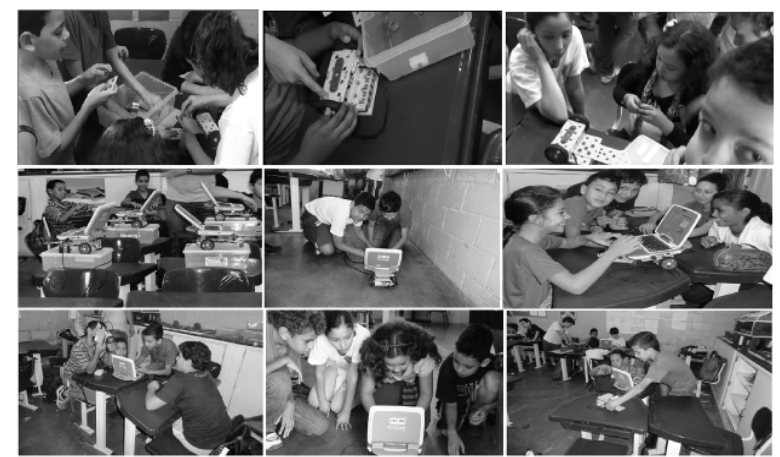

Figura 2. Sequencia de fotos dos alunos construindo e programando o carro robô

Depois de construído o carro, foi perguntado aos alunos que tipo de problemas envolvendo o objeto de estudo deles (unidades de medida) o carro robô transportando o laptop classmate poderia ajudar a explicitar. $\mathrm{Na}$ aula seguinte, uma semana depois, os alunos trouxeram uma série de problemas, alguns descritos na subseção 3.1, que o carro poderia ajudar a resolver de forma prática. A figura 3 mostra o carro construído pelos alunos.

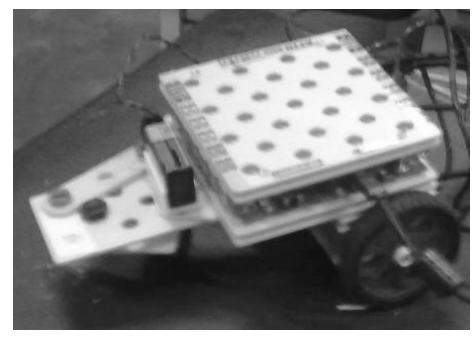

Figura 3. Carro construído pelos alunos 


\subsection{Problemas elaborados pelos alunos}

1. O robô leva o laptop em cima dele, se programarmos para girar por um minuto ele consumirá $30 \%$ da bateria, sendo que ele tem $100 \%$ de bateria quanto sobrará de bateria?

2. O robô está programado para atingir a potência 255 , digamos que o robô do outro grupo está com o triplo da potência 255. quantos ele tem a mais?

3. Na aula de robótica participam 27 alunos em 5 grupos, 5 carros robôs e 5 laptops. se em 3 segundos o carro robô roda 3 voltas, quantas voltas ele dará em 1 hora? E em 5 horas?

A aula seguinte, no contexto do projeto de formação, serviu para utilizar o carro robô para solucionar os problemas elaborados. Esse processo se deu na forma de construção de tabelas, gráficos, desenhos, uso de trena para medir distância percorrida pelo carro, enfim, uma série de registros de experimento que auxiliaram os alunos na compreensão de unidades de medida. $\mathrm{O}$ fato de os alunos possuírem um objeto concreto (carro robô) que os ajudou a elaborar um problema real pode ser uma forma de aprendizado de conceitos de medida a partir de um contexto no qual estavam envolvidos e tiveram interesse em mensurar variáveis como: tempo de duração da bateria do robô em função da tarefa por este realizada e número de voltas que o carro robô dá em uma hora. Do ponto de vista curricular, alunos de $5^{\circ}$ ano ainda não sabem formular matematicamente os problemas por eles elaborados, entretanto, ao elaborá-los formularam hipóteses que do ponto de vista experimental podem ser comprovadas ou não. Com esta atividade, buscou-se uma forma diferenciada de fazer a robótica pedagógica, que vai além do simples construir e controlar um dispositivo robótico via computador.

O software que tem sido usado para programar os robôs é o Scratch, uma linguagem de programação de fácil manipulação na qual as crianças podem trabalhar com recursos de áudio e imagem, acrescido de comandos que permitem controlar a interface eletrônica do tipo Arduino [http://www.arduino.cc]. Na interface eletrônica são conectados motores, sensores, luzes, dentre outros componentes elétricos do robô. O Sistema Operacional instalado no laptop classmate para trabalhar com robótica é o Ubuntu versão 10.04 LTS - Lucid Lynx - lançado em abril de 2010. O material utilizado para montagem é da empresa Dual System Produtos e Serviços Ltda, numa versão denominada de Kit para Educação Tecnológica e Robótica, KTR - 12. Vale salientar que este tipo de material permite integrar peças do Kit com outro material de padrão não comercial (sucata).

\section{Resultados e Discussão}

Ao iniciar as atividades de formação tanto os alunos quanto as professoras não tinham compreensão do ambiente de robótica pedagógica como um todo que envolve construção automação/programação e controle automatizado do robô. A tendência era construir algo isolado, só se deparavam com o não funcionamento dos seus construtos no momento em que tinha que integrar tudo e fazer funcionar. O não funcionamento dos robôs em muitos momentos foi importante porque envolveu a depuração do robô que foi construído e do software que foi implementado para controlá-lo. Em muitas situações o erro estava nos dois. Então, o processo de depuração se constituía em uma ação de elevada importância, porque possibilitava lançar mãos as diferentes estratégias e 
habilidades para solução daquilo que estava errado. Durante o desenvolvimento do processo de formação, tanto as professoras quanto os alunos se mostraram extremamente receptivos, envolvidos e interessados na implantação da robótica pedagógica na escola. A receptividade das professoras e dos alunos foi evidenciada por meio de um blog que produziram logo nos primeiros encontros de formação. Este blog sobre a robótica pedagógica foi inserido no blog da escola, na Rede UCA: [http://emefelza2010.blogspot.com/ 2012]. A seguir, é apresentado um trecho da opinião das professoras e de dois alunos.

Professora A, "Foi a minha primeira experiência com robótica pedagógica $e$, por sinal, muito positiva, pois aos poucos eu fui percebendo que ela é usada de forma interdisciplinar. Nas oficinas fui percebendo as competências e habilidades o tempo todo... " Usar o laptop UCA para realização do trabalho fica muito fácil, pois o mesmo permite a mobilidade, sendo assim possível o desenvolvimento de projetos colaborativos...

Professora B, “Notei também que a autoestima dos alunos foi elevada.”... Todos aceitaram o desafio. Aos poucos foram construindo o conhecimento com prazer, pois tudo era novidade... O ambiente de robótica deve ser colaborativo e preconiza o trabalho em grupo e que sempre há um problema a resolver... A metodologia usada promove o trabalho em grupo de forma lúdica...

Aluno A, "A robótica ensinou muitas coisas que eu não sabia fazer através do computador. A robótica ensinou a programar os robôs pelo computador. Ensinou também a trabalhar em equipe. O Scratch é um programa simples que todos saberiam usá-lo....

Aluno B, "Adorei as aulas de robótica. Eu aprendi que na robótica os robôs são movidos por sensores... A gente, nas aulas de robótica, aprende várias coisas interessantes...

Fazer robótica pedagógica, no contexto do projeto UCA-UNICAMP tem significado trabalhar em um ambiente que propicia, pelo menos, duas habilidades aos alunos e aos professores: construção e programação de dispositivos robóticos via laptop. Faz parte desse processo o uso prático de operações matemáticas, proporção, escala, fração, etc, que, no caso, os alunos de $5^{\circ}$ ano, estão começando a aprender. Deve-se destacar também neste processo, o importante papel do professor, pois ele é a pessoa que conhece a abrangência do currículo da sua classe e que, portanto, decide que tipo de projetos de robótica devem ser implementados para atingir seus objetivos pedagógicos. A utilização da robótica no contexto dessa proposta de formação de professores se diferencia do tradicional também pela questão da mobilidade. Isto é, tanto os professores quanto os alunos podem trabalhar com o laptop para desenvolver atividades dentro e fora da sala de aula e inclusive nas suas casas. Por exemplo, no desenvolvimento de um projeto de robótica pedagógica, que não está descrito neste trabalho, houve participação dos pais de alunos, que auxiliaram seus filhos na montagem dos robôs quando os filhos levaram o laptop para casa. Isso se constitui numa abordagem educacional diferenciada na qual os pais estão mais diretamente envolvidos. Outro aspecto relevante de se mencionar é o envolvimento da direção escolar, que no caso específico da escola Elza vem adquirindo material próprio para dar continuidade à 
atividade de robótica ao término do processo de formação, quando os pesquisadores da universidade não mais estarão atuando diretamente na escola. A robótica pedagógica faz parte na atualidade de recursos tecnológicos de muitas escolas. Todavia, o projeto UCAUNICAMP vem apontando uma mudança de paradigma na maneira como se desenvolve atividades de robótica pedagógica. Atividades que tradicionalmente eram desenvolvidas por pesquisadores em laboratórios hoje podem ser desenvolvidas, em outros espaços, por alunos do ensino fundamental e médio, utilizando computadores portáteis de baixo custo e até mesmo outros dispositivos móveis como celulares. Cabe portanto neste contexto, aos pesquisadores, professores e dirigentes escolares, mudarem também na forma de se produzir, ministrar, gerenciar e disponibilizar conteúdos curriculares. Vale também citar, do ponto de vista do estado da arte, outras referências e avanços relacionados a área de robótica educativa/pedagógica tais como:

Instituto de Robótica de Yucatán (TRIY) [http://www.triy.org/ENG/Pedagogic.htm] cuja iniciativa é contribuir para a formação de competências para o desenvolvimento de cientistas e especialistas no campo da robótica. SqueakBot: a Pedagogical RoboticPlatform[http://ieeexplore.ieee.org/xpls/abs_all.jsp?arnumber=4144945\&tag=1] , uma plataforma de ensino de robótica, utilizável por pessoas jovens, para controlar e simular vários dispositivos robóticos.

\section{Conclusões}

$\mathrm{Na}$ atividade de formação desenvolvida foi necessário primeiro, realizar oficinas de sensibilização e palestras para professores alunos e direção escolar. Segundo, iniciar a formação das professoras interessadas em trabalhar com este tema. Terceiro, realizar oficinas com as professoras em sala de aula. Quarto, acompanhar a atuação das professoras sem a presença de pesquisadores da universidade. Com esta metodologia, tem se desenvolvido um projeto cujo objetivo é a formação de professores para a apropriação de conhecimentos da robótica como recurso integrado ao currículo do Ensino Fundamental I. Assim, está sendo realizada, paulatinamente, na escola Elza, a integração de mais uma tecnologia educacional na atividade curricular dos alunos de quinto ano. Na medida em que os professores estão se apropriando de conhecimentos nesta área estão tornando-se autônomos em trabalhar com os alunos sem a presença de pesquisadores da universidade. Isso, de certa forma, evidencia-se como uma garantia da continuidade da realização da atividade de robótica na escola mesmo depois de finalizado o projeto UCA-UNICAMP. Vale ressaltar que atuação dos pesquisadores da universidade na escola, teve sempre que se adequar a dinâmica de funcionamento da rede municipal de Campinas que contou com greves, paralisações, e outros fenômenos que fazem parte da vida do brasileiro. Entretanto a esperança é que a prática de robótica pedagógica, que é uma área atraente para as crianças e também para os pais, se solidifique na escola Elza Maria Pellegrini de Aguiar.

\section{Agradecimentos}

Os autores agradecem a coordenação do projeto UCA-UNICAMP, ao CNPq, pelo apoio ao projeto "O Laptop Educacional e a Educação Baseada na Investigação: do estudo de fatos científicos para o fazer científico" (550382/2011-9), aos professores, alunos e direção da escola Elza e, aos mestrandos e bolsistas de Iniciação Científica. É com a colaboração de todos que este trabalho de formação tem sido realizado. 


\section{Referências}

Arduino "Open-source physical computing platform". Disponível em $<$ http://www.arduino.cc/>. Acesso em 20 Julho de 2013.

Conheça o UCA. Disponível em <www.uca.gov.br/institucional/projeto.jsp > Acesso em 24 de Setembro de 2013.

d'Abreu, J. V. V. Bastos, B. L., Giachetto, G. F. A. O. (2012), Educational Robotics In One Laptop per Student-UCA Project In: Constructionism 2012, Athenas. Constructionism 2012_proceedings. v.01. p.575 - 579.

d'Abreu J. V. V, Garcia, M. F. (2010) Robótica Pedagógica e Currículo In: Workshop de Robótica Educacional WRE - 2010, SBIA-SBRN-JRI, São Bernardo do Campo SP,. Brasil, p.01 - 06 .

d'Abreu, J. V. V. Ramos, J. G., Mirisola Luiz G. B. (2011), Ambiente de Robótica Pedagógica com Br-GoGo e Computadores de Baixo Custo: Uma Contribuição para o Ensino Médio In: 22 $2^{\circ}$ Simpósio Brasileiro de Informática na Educação e $17^{\circ}$ Workshop de Informática na Escola, Aracaju. Anais do Simpósio Brasileiro de Informática na Educação,v.01.p.100 - 109.

EMEF.Elza - na Rede UCA (2012). Disponível em <http://emefelza2010.blogspot.com>. Acesso em 24 de Setembro de 2013.

Garcia, M. F. (2002), O Ensino por Meio da Pesquisa: O projeto Ciência na Escola. Tese de doutorado. Faculdade de Educação, FE-UNICAMP, Campinas, SP, Brasil, p. 43.

Instituto de Robótica de Yucatán (TRIY), (2012). The Robotics Institute of Yucatán http://www.triy.org/ENG/Pedagogic.htm. Acesso em 24 de Setembro de 2013.

Miranda, L. M., Sampaio F. F., Borges J. A. S. (2010), RoboFácil: Especificação e Implementação de um Kit de Robótica para a Realidade Educacional Brasileira. Disponível em <http://www.br-ie.org/pub/index.php/rbie/issue/view/39>, RBIE V.18 N.3 - 2010, acesso em 23 de Julho de 2013.

Papert, S. (1994), A Máquina das Crianças: Repensando a Escola na Era da Informática. Porto Alegre, Artes Médicas, RS, Brasil.

Passos L. F. (1997), A Colaboração do Professor-Pesquisador no Processo de Formação em Serviço dos Professores da Escola Básica. Tese de Doutorado Universidade de São Paulo - USP, São Paulo, SP, Brasil, p. 3.

SqueakBot a Pedagogical Robotic Platform (2013)

Disponível em [http://ieeexplore.ieee.org/xpls/abs_all.jsp?arnumber=4144945\&tag=1]. Acesso em 26 de Setembro de 2013.

Zanetti, H. A. P. d'Abreu, J. V. V, Souza, A. L. S., Borges, M. A. F. (2012), Uso de Robótica e Jogos Digitais Como Sistema de Apoio ao Aprendizado In: CBIE 2012 Congresso Brasileiro de Informática na Educação, 2012, Rio de Janeiro - RJ. Anais do CBIE 2012 Congresso Brasileiro de Informática na Educação. Porto Alegre: SBC, v.01. p. $145-164$. 